\title{
MATHEMATICAL MODEL OF INDIVIDUAL LUBRICATION SYSTEM FOR BEARING ASSEMBLY OF INTERNAL COMBUSTION ENGINE TURBOCHARGER
}

\author{
Robert Galimov ${ }^{1}$, Ilgiz Galiev ${ }^{1}$, Alexander Kulakov ${ }^{2}$, Engel Galimov ${ }^{3}$ \\ ${ }^{1}$ Kazan State Agrarian University, Russia; \\ ${ }^{2}$ Kazan (Volga region) Federal University (Naberezhnye Chelny Institute of KFU), Russia; \\ ${ }^{3}$ Kazan National Research Technical University named after A. N. Tupolev, Russia \\ galimov2507@gmail.com,drgali@mail.ru, alttrak09@mail.ru,89871726737@mail.ru
}

\begin{abstract}
Annotation. Internal combustion engines are equipped with turbochargers to increase their power, while the design of the engine itself practically remains unchanged. The turbocharger operates at high rotor speeds $(25000$ $\left.\ldots 110000 \mathrm{~min}^{-1}\right)$, as well as at high temperature conditions $\left(650 \ldots 700{ }^{\circ} \mathrm{C}\right)$. The problem is compound by the fact that the bearing assembly receives a lubricant that was involved in lubrication of the rubbing elements of the entire engine, since the turbocharger bearing lubrication system is combined with the engine lubrication system. This leads to increased wear on the turbocharger bearing and a reduction in its service life. These circumstances require an increase in the lubrication efficiency of the turbocharger-bearing unit. To solve this problem, we have developed a new design of an individual lubrication system for the internal combustion engine turbocharger bearing. The design solution allows to provide the turbocharger bearing assembly with lubricant in the engine start mode and after it stops during the rotation of the rotor by inertia for 90 seconds. The article deals with the design calculation of the individual turbocharger bearing lubrication system. In order to be able to calculate the design of an individual turbocharger bearing lubrication system for any engine, a mathematical model has been developed. The final formulas for calculating the parameters of the turbocharger bearing lubrication system are present, as well as specific calculation results for the most common brand of turbocharger.
\end{abstract}

Keywords: efficiency of the turbocharger, autonomous system of lubrication, calculation of parameters of the lubricating system.

\section{Introduction}

Agricultural production is one of the main sectors of the country's economy, which constantly needs to attract mobile energy resources to perform technological processes in crop production and animal husbandry [1;2]. The most promising way to meet the needs of the agro-industrial complex in energy resources is to increase their unit capacity [3;4].

Increasing the unit power of the internal combustion engine is associated with the use of a turbocharger. This method is widely used, since it does not require changing the internal design parameters of the engine, while it leads to a significant $(40 \ldots 50 \%)$ increase in their power $[5 ; 6]$. However, the lack of reliability of the turbochargers leads to a decrease in the efficiency of their use, which leads to long downtime of equipment, especially during busy production cycles $[7 ; 8]$.

As a result of the research, it was found that the number of failures increases with increasing wear and tear of equipment, which will eventually lead to an increase in the recovery period [2]. In this regard, research aimed at ensuring the performance of systems and units, as well as tractors and agricultural machines in general, is relevant.

Performance indicators, performance, fuel efficiency and reliability of equipment directly depend on the conditions and intensity of loads on tractor engines, which are characterized by frequent and abrupt changes of modes. Increased wear, reduced technical and economic indicators and engine power are associated with frequent starts and long stops of diesel engines, as well as short-term overloads, significant periods of acceleration and braking $[9 ; 10]$.

A special feature of the turbocharger installed on automobile diesel engines is the compressor drive itself, which pumps air into the engine cylinders, which is carried out by means of a turbine. The turbine is driven in rotation by the exhaust gases of the engine itself, it has a common shaft with the compressor and sliding bearing. The turbocharger bearing operates under extremely negative conditions, since the exhaust gas temperature is $700{ }^{\circ} \mathrm{C}$, which affects the turbine and the bearing. Since the oil entering the turbocharger bearing assembly participates in lubrication of the rubbing elements of the entire engine, it soon loses the quality that ensures the reliability of the turbocharger operation.

Thus, the bearing unit of the turbocharger is the object of the entire engine lubrication system, on the one hand, and the lubricant that participates in the lubrication of all rubbing elements soon loses its performance, on the other, which reduces the reliability of the turbocharger $[11 ; 12]$. Moreover, the 
turbocharger rotor develops a rotation speed from 15000 to $90000 \mathrm{~min}^{-1}$, while, structurally, there is no rigid kinematic connection with the oil pump, which leads to a long run-out of the rotor without the supply of lubricant. This circumstance leads to a sharp increase in the temperature in the bearing unit, coking of the oil and accelerated wear of the bearings.

One of the ways to solve the problem of improving the operational reliability of a diesel engine turbocharger is to improve the lubrication system of its bearing.

\section{Materials and methods}

We have developed an individual lubrication system for the turbocharger bearing. The use of an individual lubrication system for the turbocharger bearing ensures its operation regardless of the standard engine lubrication system. In this case, it is possible to lubricate the bearing of the turbocharger already in the starting mode of the engine, during its operation and after stopping. The presence of a hydrobattery in the design of the individual turbocharger bearing lubrication system allows to continue to lubricate the rotating parts of the turbine by inertia until they are completely stopped after stopping the engine.

For smooth operation of the individual lubrication system of the turbocharger bearing, it is necessary to develop its mathematical model, which involves calculations for all types of engines with different models of turbochargers. When calculating the oil consumption through various elements of the diesel engine lubrication system, you can use the general equation of the expense balance [5]:

$$
G_{k}=G_{k}\left(\Delta p_{k} v_{k}\right),
$$

where $G_{k}$-oil flow, $1 \cdot \mathrm{s}^{-1}$;

$\Delta p_{k}$ - pressure loss across the element of the oil system, MPa;

$v_{k}$ - dynamic oil viscosity, $\mathrm{Pa} \cdot \mathrm{s}$.

The oil flow $\left(G_{k}\right)$ through any element of the lubrication system is a function of the loss of the pressure value and the dynamic viscosity of the oil on it $\left(v_{k}\right)$.

The oil flow balance for a system consisting of $n$ nodes can be recorded $[5 ; 6]$ :

$$
\sum_{k=1}^{K_{i}} G_{k}\left(\Delta P_{k} v_{k}\right)=\sum_{m=1}^{M_{i}} G_{m}\left(\Delta P_{m} v_{m}\right),
$$

where $G_{k}\left(\Delta p_{k} v_{k}\right)$ - amount of the oil flow in the k-th branch, at the entrance to the $i$-th node $(K-$ number of corresponding branches), $1 \cdot \mathrm{s}^{-1}$;

$G_{m}\left(\Delta p_{m} v_{m}\right)$ - oil flow in the $m$-th branch, at the exit of the $i$-th node ( $M$ - number of such branches), $1 \cdot \mathrm{s}^{-1}$.

\section{Results and discussion}

To develop a mathematical model of an individual turbocharger bearing lubrication system (Fig. 1), it is necessary to divide it into sections. Each section corresponds to the length of the lubricant path traveled without changing the external and internal conditions: segment (A) - of oil movement from the oil pump to the filter of fine cleaning oil; segment (B) - of the oil movement from of fine cleaning oil to the general tee of the turbocharger; segment $(\mathrm{C})$ - of oil movement from the common tee to the hydrobattery; segment (D) - of oil movement from the hydrobattery to the common tee providing lubricant for the turbocharger bearing; segment $(\mathrm{E})$ - of oil movement from the common tee providing lubricant for the turbocharger bearing to the bearing; segment $(\mathrm{F})$ - of oil movement from the oil tank to the oil pump.

Since we know the parameters of the lubrication mode of the turbocharger bearing assembly (nominal volume of oil consumption $\left(Q_{0}\right)$; nominal oil pressure in the turbocharger bearing $\left(P_{0}\right)$ ), calculations were made from the end of the oil line, that is, from the turbocharger bearing. The diameters of the oil pipes are determined from the expressions (segments (E), (D), (C), (B) and (A)):

$$
d_{E}=\sqrt{\frac{4 Q_{0}}{\pi V_{E}}}, d_{D}=\sqrt{\frac{V_{n}}{\mu_{c} \pi t_{u}} \sqrt{\frac{8 \rho}{P_{h}}}}, d_{C}=\sqrt{\frac{V_{n}}{\mu_{c} \pi t} \sqrt{\frac{8 \rho}{P_{0}}}}, d_{B}=\sqrt{\frac{4 Q_{0}}{\pi V_{B}}}, d_{A}=\sqrt{\frac{4 Q_{0}}{\pi V_{A}}},
$$


where $V_{E}-$ oil flow rate in the segment $(\mathrm{E}), \mathrm{m} \cdot \mathrm{s}^{-1}$.

$V_{n}$ - useful volume of the hydrobattery, $\mathrm{m}^{3}$;

$\rho$ - oil density, $\mathrm{kg} \cdot \mathrm{m}^{-3}$;

$P_{h}$ - nominal oil pressure in the bearing, $\mathrm{MPa}$;

$\mu_{\mathrm{c}}-$ coefficient of oil consumption from the hydrobattery;

$t_{u}$ - time of rotation of the rotor of the turbocharger after the engine stop, s.

$t$ - charging time of the hydrobattery, s.

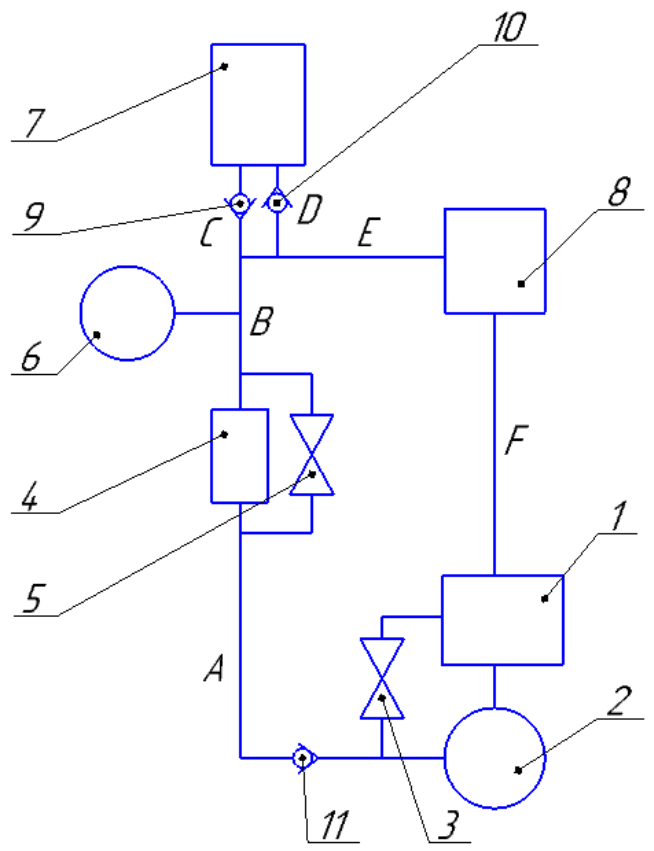

Fig. 1. Scheme of individual lubricant system bearing engine turbocharger: 1 - oil tank; 2 - oil pump; 3 - valve of pressure reducing; 4 - oil filter; 5 - bypass valve; 6 - sensor of pressure;

7 - hydrobattery; 8 - bearing of the turbocharger; 9 - reverse valve at the entrance to the hydrobattery;

10 - reverse valve at the exit of the accumulator; 11 - reverse valve of the lubrication system of the bearing of the turbocharger

Taking into account the pressure loss in all sections, the pressure generated by the oil pump can be determined by the formula:

$$
\begin{aligned}
& P_{n}=P_{0}+\Delta P_{E}+\Delta P_{C}+\Delta P_{B}+\Delta P_{A}+\Delta P_{V R}= \\
& =P_{0}+\frac{128 v \rho Q_{0}}{\pi}\left(\frac{L_{E}}{d_{E}^{4}}+\frac{L_{B}}{d_{B}^{4}}+\frac{L_{A}}{d_{A}^{4}}+\frac{Q_{0}}{16 \pi d_{B}^{4}} \xi_{F}\right)+\frac{32 v L_{C} \rho\left(Q_{0} \pi d_{C}^{2}-4 Q_{C}\right)}{\pi d_{C}^{4}}+\frac{0,5 \rho Q_{0}}{\mu_{v r} \pi d_{v r} h_{z} \sin \beta_{v r}},
\end{aligned}
$$

where $\Delta P_{E}, \Delta P_{C}, \Delta P_{B}, \Delta P_{A}, \Delta P_{V R}-$ accordingly, the loss of pressure at sections (A), (B), (C), (E) and the valve of pressure reducing, MPa;

$L_{E}, L_{C}, L_{B}, L_{A}$ - accordingly, length of the oil line tubes at sites (E), (C), (B), (A), m;

$v$ - kinematic viscosity, $\mathrm{m}^{2} \cdot \mathrm{s}^{-1}$;

$\mu_{\mathrm{vr}}$ - ratio of the oil flow through the valve of pressure reducing;

$\xi_{F}-$ resistance coefficient of the filter of thin clearing oils;

$h_{z}$ - lift height of the valve of pressure reducing, m;

$\beta_{v r}$ - angle of the cone of saddle of the valve of pressure reducing, grad.

The required pump supply is determined taking into account the separation of the oil flow into two parts during filling of the hydrobattery of the turbocharger:

$$
Q_{n}=Q_{0}+Q_{B}=Q_{0}+\frac{\mu_{c} \pi d_{B}^{2}}{4} \sqrt{\frac{2 P_{0}}{\rho}},
$$

Power of the pump is determined by the formula: 


$$
\begin{aligned}
& N_{n}=\left(P_{0}+\frac{128 v \rho Q_{0}}{\pi}\left(\frac{L_{\not}}{d_{E}^{4}}+\frac{L_{B}}{d_{B}^{4}}+\frac{L_{A}}{d_{A}^{4}}+\frac{Q_{0}}{16 \pi d_{B}^{4}} \xi_{F}\right)+\frac{32 v L_{C} \rho\left(Q_{0} \pi d_{C}^{2}-4 Q_{C}\right)}{\pi d_{C}^{4}}+\right. \\
& \left.+\frac{0,5 \rho Q_{0}}{\mu_{v r} \pi d_{v r} h_{3} \sin \beta_{v r}}\right) \cdot\left(Q_{0}+\pi^{2} d_{C}^{2} d_{E}^{2} \sqrt{\frac{v L_{C}}{8 Q_{0} \kappa_{0}\left(P_{0} \pi d_{E}^{4}+128 v L_{E} Q_{0}\right)}}\right) .
\end{aligned}
$$

The calculation of the oil filter consists in determining the area of its filter element:

$$
F_{F}=\frac{120 Q_{n} v}{C \eta_{n} \xi_{F} \rho V_{B}^{2}},
$$

where $C$-coefficient that depends on the type of the filter element;

$\eta_{n}$ - pump feed coefficient that takes into account oil leaks through the gaps.

Calculation of parameters of the oil tank. It is most appropriate to produce flat and cubic tanks. The calculated cooling surface is equal to:

$$
F=\frac{1,4 N_{\mu n}\left(1-\eta_{\text {м.н. }}\right)+\mathrm{W}_{m \kappa p}}{K \eta_{\mu}\left(\mathrm{T}-\mathrm{T}_{o}\right)},
$$

where $K$ - coefficient of heat transfer from the oil through the steel wall to the air, $\mathrm{kJ} / \mathrm{m}^{2} \cdot \mathrm{s} \cdot \mathrm{grad}$;

$T$ - maximum permissible temperature of the oil in the tank, grad;

$T_{o}$ - ambient temperature, grad;

$W_{t}$-amount of heat that must be removed from the bearing of the turbocharger, $\mathrm{kJ} \cdot \mathrm{s}^{-1}$.

The length of the sides of the oil tank is determined by the formula:

$$
a=b=c=\sqrt{\frac{F}{6}} .
$$

At the same time, the condition must be met, the volume of the oil tank must be greater than the required amount of oil located in the turbocharger bearing lubrication system:

$$
V_{t} \succ V_{c a}+V_{h a}+V_{f},
$$

where $V_{c a}-$ volume of oil in the hydrobattery after full charge, $\mathrm{m}^{3}$;

$V_{h a}$ - volume of oil in the pipelines of the lubrication system, $\mathrm{m}^{3}$;

$V_{f}$ - volume of oil in the fine filter, $\mathrm{m}^{3}$.

Determination of the hydrobattery operating parameters. Determining the operating parameters of the hydrobattery is carried out based on the minimum design volume and the specified range of the operating pressure (from $P_{\max }$ to $P_{\min }$ ), on the one hand, and ensuring the maximum useful capacity of the battery - on the other. The initial parameters for determining the volume of the hydrobattery are the minimum and maximum working pressures, as well as the useful capacity of the hydrobattery. The design volume of the hydrobattery is determined from the formula:

$$
V_{t v}=\frac{V_{u}}{\frac{0.9 P_{\min }^{1 / I}}{P_{\text {min }}}-\frac{0.9 P_{\min }^{1 / I}}{P_{\text {max }}}},
$$

where $V_{t v}-$ total volume, $\mathrm{m}^{3}$;

$V_{u}$ - useful volume of oil displaced from the battery from $P_{\max }$ to $P_{\min }, \mathrm{MPa}$;

$I$ - isothermal law; $P_{\max }, P_{\min }-$ maximum and minimum pressure, MPa.

The volume of the gas chamber is determined from the formula:

$$
V_{g}=\frac{V_{u}}{\left(\frac{P_{\max }}{P_{\min }}\right)^{1 / I}-1} .
$$

The dimensions of the hydrobattery cylinder are determined based on the optimal ratio of diameter to length: 


$$
L_{l}=k_{r} d_{h a}
$$

where $L_{l}$ - length of the hydrobattery cylinder, $\mathrm{m}$;

$K_{r}$ - ratio of the length to the diameter of the hydrobattery cylinder, m;

$d_{h a}$ - diameter of the hydrobattery cylinder, $\mathrm{m}$.

Then the diameter of the cylinder of the hydrobattery can be determined by the formula:

$$
d_{h a}=\sqrt[3]{\frac{4 V_{t v}}{k_{r} \pi}} .
$$

The calculation and selection of the thickness of the wall of the hydrobattery is carried out taking into account the strength requirements. The internal pressure of structural destruction is taken from the calculation:

$$
P_{P}=f_{s} P_{\max }
$$

where $f_{s}$ - safety coefficient.

The wall thickness, from the strength condition, is found by the formula:

$$
S=\frac{P_{P} d_{h a}}{4 \sigma},
$$

where $\sigma$-strength limit, MPa.

To develop an experimental sample of an individual turbocharger lubrication system, we must select a specific brand of turbocharger. The choice should be guided by the fact that this model of turbocharger is widely used not only on trucks, but also on tractor engines that operate in the most difficult production conditions, both in industry and in agriculture. The TKR-11 turbocharger is very popular, as it is installed on well-known models of engines of cars and tractors.

Table 1 shows the results of implementing a mathematical model of an individual bearing

\begin{tabular}{|c|c|c|c|}
\hline Indicator & Designation & Unit & Parameter value \\
\hline Oil pressure in the bearing of the turbocharger & $P_{0}$ & $\mathrm{MPa}$ & 0.4 \\
\hline Oil supply in the bearing of the turbocharger & $Q_{0}$ & $\mathrm{~m}^{3} \cdot \mathrm{s}^{-1}$ & 0.000033 \\
\hline Oil flow rate in the pipe $(\mathrm{E})$ & $V_{E}$ & $\mathrm{~m} \cdot \mathrm{s}^{-1}$ & 2.5 \\
\hline \multicolumn{4}{|c|}{ Segments length: } \\
\hline Tee - the bearing of the turbocharger & $L_{E}$ & $\mathrm{~m}$ & 0.3 \\
\hline Hydrobattery - tee (yield of oil) & $L_{D}$ & $\mathrm{~m}$ & 0.15 \\
\hline Tee - hydrobattery (oil inlet) & $L_{C}$ & $\mathrm{~m}$ & 0.15 \\
\hline Tee - filter & $L_{B}$ & $\mathrm{~m}$ & 0.5 \\
\hline Filter - pump & $L_{A}$ & $\mathrm{~m}$ & 1 \\
\hline Oil pump supply & $Q_{n}$ & $\mathrm{~m}^{3} \cdot \mathrm{s}^{-1}$ & 0.000042 \\
\hline Pressure generated by the pump & $\widetilde{P} P_{n}$ & $\mathrm{MPa}$ & 0.52 \\
\hline Required pump power & $N_{n}$ & $\kappa V_{T}$ & 0.022 \\
\hline Area of the filter element & $F_{f}$ & $\mathrm{~m}^{2}$ & 0.01384 \\
\hline Volume of the hydraulic tank & $V_{t}$ & 1 & 10 \\
\hline \multicolumn{4}{|c|}{ Hydrobattery options } \\
\hline Cylinder length & $L_{h a}$ & $\mathrm{~m}$ & 0.203 \\
\hline Diameter of the cylinder & $D_{h a}$ & $\mathrm{~m}$ & 0.203 \\
\hline Diameter of the intake hole & $d_{d}$ & $\mathrm{~m}$ & 0.0015 \\
\hline Diameter of the prom hole & $d_{c}$ & $\mathrm{~m}$ & 0.003 \\
\hline Charging time & $t$ & $\mathrm{~s}$ & 392.4 \\
\hline Diameter of the oil lines & $D_{A, B, E}$ & $\mathrm{~m}$ & 0.005 \\
\hline
\end{tabular}
lubrication system for an internal combustion engine turbocharger.

\section{Initial data and results of calculations of the individual lubrication system of the bearing for the TKR-11 turbocharger (YAMZ-238L engine)}




\section{Conclusions}

The individual turbocharger bearing lubrication system makes it possible to use special turbine oils of synthetic origin that are not prone to coking, have higher stability when working with high temperatures and the ability to adapt to changing operating conditions during operation, which increases the durability of the turbocharger.

The developed mathematical model allows: to calculate all parameters of the individual bearing lubrication system of the turbocharger, that is, to determine the values of all design parameters of the lubrication system (of the parameters of the oil pump, of the hydrobattery, of the oil pipes, of the fine filter), which are necessary for production of a working sample of the individual bearing lubrication system.

\section{References}

[1] Nuriev L.M., Yakhin S.M., Aliakberov I.I., Galiev I.G., Sinitsky S.S. Kinematics and parameters for spiral-helical machinery unit used for secondary tillage // International Conference on Technological Solutions and Instrumentation for Agribusiness: Earth and Environmental Science Volume 488, Issue 1, Stavropol; Russian Federation, 2020.

[2] Galiev I.G., Khafizov K.A., Khusainov R.K., Faskhutdinov M.Kh. Ensuring possibility of functioning of tractors in agricultural production taking into account residual resources of their units and systems //19th International Scientific Conference Engineering for rural development Proceedings, Volume 18 May 22-24, 2020, pp. 48-53.

[3] Khafizov C.A., Khafizov R.N., Nurmiev A.A., Galiev I.G. Optimization of main parameters of tractor and unit for plowing soil, taking into account their influence on yield of grain crops //19th International Scientific Conference Engineering for rural development Proceedings, Volume 18 May 22-24, 2020 pp. 585-590.

[4] Fedyaev V.L., Galimov E.R., Belyaev A.V., Dolgov A.V., Samoylov V.M. Evaluation of interphase boundaries dynamics at the contact of melt with solid materia // IOP Conf. Series: Materials Science and Engineering 412 (2018) 012015. DOI: 10.1088/1757-899X/412/1/012015

[5] Burtsev A.Yu. Improving the operational reliability of internal combustion engine turbochargers // Materials of the III international scientific and technical conference "Achievements of science in agro-industrial production" edited by N. S. Sergeev. Chelyabinsk, 2013. pp. 28-34.

[6] Plaksin A.M. [and others] the extension of the service life of turbochargers automotive vehicles use a hydraulic accumulator in the oil system // Fundamental research. 2014. No. 6. Part 4. pp. 728732.

[7] Denisov A.S., Korkin A.A. Optimization of the parameters of the hydraulic accumulator of oil for a turbocharger // Improving technologies and organizations for ensuring the working capacity of machines: a collection of scientific papers $\cdot \mathrm{s}^{-1}$ aratov State Technical University. Saratov, 2010. pp. 21-27.

[8] Kruglov M.G., Mednov A.A. Gas dynamics of combined internal combustion engines. Moscow: Mashinostroenie, 1988. 360 p.

[9] Prolongation of the service life of turbochargers of automotive equipment using a hydraulic accumulator in the lubrication system/A.M. Plaksin [and others] // Fundamental Research. 2014. No. 6. Part 4. pp. 728-732.

[10] Savelyev G.M., Lyamtsev B.F., Aboltin E.V. Experience in the development and production of turbochargers for automobile engines. - M., 1986. 123 p.

[11] Stechkin S.B., The theory of heat engines. Selected Works. Moscow: Nauka, 1977. 412 p.

[12] Kolchin A.I., Demidov V.P. Calculation of automobile and tractor engines. 2nd ed. Moscow: High school, 1980. 400 p.

[13] Khanin N.S. Additional air supply and superchargers of automobile engines. - M.: Mashinostroenie, 1965. $187 \mathrm{p}$. 